\title{
The Execution of Key Performance Indicators in the Operational Phase of PFI Projects in Malaysia
}

\author{
Nor Suzila Lop ${ }^{1}$, Kharizam Ismail2, Haryati Mohd Isa² \\ ${ }^{1}$ Centre of Postgraduate Studies, \\ 2 Faculty of Architecture Planning and Surveying, \\ Universiti Teknologi MARA, Seri Iskandar Campus, Seri Iskandar, 32610, Perak, Malaysia. \\ norsu993@perak.uitm.edu.my
}

\begin{abstract}
In Private Finance Initiative (PFI), payment for services is based on pre-determined standards and performance. Thus, Key Performance Indicators (KPIs) have been used to measure this performance. However, lack of an effective KPIs was identified as a core criticism towards the execution of PFI projects. Therefore, the objectives of the research are to determine the importance and challenges of KPIs in measuring this performance. A qualitative approach via semi-structured interview was adopted. The findings discovered that the current KPIs do not meet the criteria and this can lead to the difficulties in measuring the performance of PFI projects. The outcome of this research can serve as a theoretical base for the development of an effective KPIs for PFI projects implementation in Malaysia.
\end{abstract}

eISSN 2398-4279 @ 2018. The Authors. Published for AMER ABRA cE-Bs by e-International Publishing House, Ltd., UK. This is an open access article under the CC BY-NC-ND license (http://creativecommons.org/licenses/bync-nd/4.0/). Peer-review under responsibility of AMER (Association of Malaysian Environment-Behaviour Researchers), ABRA (Association of Behavioural Researchers on Asians) and CE-Bs (Centre for EnvironmentBehaviour Studies), Faculty of Architecture, Planning \& Surveying, Universiti Teknologi MARA, Malaysia.

DOI: https://doi.org/10.21834/ajqol.v3i12.152 


\subsection{Introduction}

In Malaysia, a new wave of privatisation has been implemented under the Tenth Malaysian Plan to increase private investment in the economy, improve efficiency in the delivery of services and relieve the financial burden of the Government. PFI is viewed as restructuring the previous privatisation concept in delivering value for money (VFM) for Malaysian public infrastructure. Among the many restructuring efforts in the privatisation is specifying the standard assessment of private concessionaires' performance through the execution of key performance indicators (KPIs) where it is benchmarked against the government's standard. Essentially, the PFI program was aimed at facilitating greater participation of the private sector to improve the delivery of infrastructure facilities and public services (Prime Minister Department, 2009). As such, Rusmani (2010) in his research indicated that the introduction of several policies involving both the public and private in delivering the public projects was a measure to enforce the relationship between the two sectors. Therefore, the rationale of utilising the PFI procurement in Malaysia is to provide better and more efficient public services by sharing resources between public and the private sectors (Takim et al., 2008).

PFI procurement scheme in Malaysia is still at an infant stage, and the concept of PFI is lagging behind compared to other experienced countries such as UK and Australia. One of the issues experienced by the Malaysian government is regarding assessment of PFI projects performance. The lack of effective performance measurement tool to measure the project performance is identified as a factor that leads to the poor project performance in Malaysia (Ismail, 2012; Khaderi \& Aziz, 2010).Therefore, the establishment of a framework is vital to provide a better understanding of the execution of the complex scheme of financing, as well as the establishment of the KPIs for assessing overall projects' performances. Despite the tremendous growth of PFI implementation in Malaysia, the PFI arrangements have continually been reviewed and revised by the Malaysian government to improve the present practice of $\mathrm{PFI}$ implementation to ensure the achievement of its ultimate goal and objectives.

Fundamentally, PFI projects are designed to fund long-term public infrastructures and services provided for the whole life cycle of PFI projects. During this period, PFI performances could be affected by many factors, which might cause the inefficiency and ineffectiveness of the projects. For instance; defects occurrence (Isa et al., 2016; Universiti Teknologi MARA, 2016); complaints from users on inadequate facilities and services provided; low level of users' satisfaction (Universiti Teknologi MARA, 2015; 2016); and conflict between payment and measuring performance (Oyedele, 2013; Yescombe, 2008). These factors can contribute to the PFI poor performance and consequently will affect the payment process. Therefore, payment deduction will be imposed to the poor or low level of performance standard achieved by the concessionaire (Oyedele, 2013). According to NAO (2010), service failure and poor performance in maintenance work for non-compliance with output specification are frequently reported within PFI projects in the UK and Australia. This result will affect the success of a PFI project implementation and consequently be failed to achieve VFM. Factors that will influence this performance should be measured before any deductions and determination level of performance are imposed. Hence, to measure the level 
of PFI projects performances, the establishment, and selection of an effective performance measurement tools is a necessity.

To measure the performances of the projects and for applying a benchmarking approach, the establishment of suitable KPIs in PFI is essential in determining the overall success of the projects. However, lack of an effective performance measurement in PFI will be reflected from the depreciation of standards below optimum service quality of infrastructures. This circumstance will contribute to the failures delivery of PPP projects (Liu et al., 2015; Liu et al., 2013; Mladenovic et al., 2013; Regan et al., 2011; Yong, 2010; Yuan et al., 2009; Hodge, 2004; House of Commons, 2003; VAGO, 2002). According to Robinson \& Scott (2009), VFM in the PFI project crucially depends on performance monitoring to provide certain incentives for improvement and to ensure that the service delivery is following the client's requirement, as was set out in the output specification. Besides, the clients of the public sector can attain full VFM from the usage of assets that meets their requirements, consequently satisfying the principal objectives of the PFI procurement mechanism (Oyedele, 2013).

Even though a lot of studies on KPIs have been conducted, nonetheless, KPIs are still continuously debated. For instance; lack of clarity and understanding of KPIs for PFI projects (Lawther \& Martin, 2014; Javed et al., 2013a; David \& Steve, 2012) and insufficient effective performance indicators for measuring quality of the service delivery (Oyedele, 2013; Javed et al., 2013b; Toor \& Ogunlana, 2010). The agreeing level of performance can determine the amount of payments or deductions from the public sector to the private sector. Consequently, if the quality of service does not achieve the minimum standards stipulated in the output specification, a payment deduction or penalties can be triggered in the form of a performance failure payment deduction (Yescombe, 2008). Therefore, this paper aims to explore the adoption of KPIs in the operational stage of PFI projects in Malaysia by identifying the importance and challenges of the KPIs in measuring the performance.

\subsection{Literature Review}

\section{KPIs Implementation in PFI Projects}

$\mathrm{KPIs}$ is defined as a more specific milestone in or components of performance measures that serves as precursors to indicate progress towards the eventual achievement of the desired performance measures (Molenaar et al., 2011). The precise definitions were elucidated by the Centre for Construction Innovation for Constructing Excellence in the North West (2006), where KPI was defined based on every single word that formed the KPI terminology. The term "key" relies on how to define when a project is successful, while "performance" means how the success is demonstrated, and "indicator" is definite on how to measure success. From the various perceptions on the meaning of KPIs, it is clearly defined that KPI is a systematic data compilation used to measure performances concerning to specific success factor.

The primary principle of PFI is the link between performance and incentive payments to the private sector based on successful delivery of services to the public sector. However, the service delivery aspects of PFI projects cannot be examined until the projects become 
operational (Yuan et al, 2009). During the operational phase, services delivery can frequently be measured to determine its compliance with the output specification and payment deductions for the performance failures in accordance with the payment mechanism (Akbiyikli, 2013). In PFI projects, KPIs act as a useful tool to measure the performance of PFI projects at different levels and stages of the project. The U.K NAO (2003) acknowledged that most PFI contracts use KPIs as a benchmarking tool for contractors' evaluation with regards to service delivery.

To measure the performance of PFI projects, determination of appropriate KPI is important to be emphasised (Yuan et al., 2009). The used of KPIs as a performance measurement tool can be used to identify the strengths and weaknesses of PFI projects and can be applied effectively in the performance management of PFI projects (Mladenovic et al., 2013). It is supported by the study from Mladenovic et al. (2013); Cox et al. (2003); and Kagioglou et al. (2001) that, KPIs are identified as one of the popular tools used in measuring the performance of PFI projects. Therefore, they have referred the KPIs as compilations of data measures used to assess the performance of construction operations. The most prominent benefit of using KPI in PFI is its ability in benchmarking the concessionaire performance against other PFI projects, where the lessons learned from the best can be exploited to make a targeted improvement. In conjunction with PFI for public infrastructure projects, KPIs for PFI allow greater public participation in the formation of those KPIs where it is anticipated that these KPIs assist in making PFI more significant to public needs and requirement instead of beneficial mostly to profit-driven private concessionaries (Ismail, 2009).

\subsection{Methodology}

This research presents the findings of the preliminary survey, which adopted the qualitative approach through a semi-structured interview. This semi-structured interview consists of several questions aimed to identify the importance and challenges of KPIs implementation in the Malaysia PFI projects. A total of 10 participants from PFI practitioners is involved in the interview process. Inputs from the experts and their views are needed in obtaining the real issues regarding KPIs' implementation in Malaysia PFI projects. The transcription and interpretation from the semi-structured interview findings will be carried out using Atlas.ti7○ qualitative software. A semi-structured interview was selected because it comprises a combination of two different types of questions namely structure and open questions (Sarantakos, 2012).

The questions for the semi-structured interview are prepared in the interview form. Semistructured face-to-face interviews were exploited to obtain demographic data and to also determine the importance and challenges of KPIs for PFI projects in Malaysia. The instrument drafted consist of a cover page and was divided into three sections. The first section (Section A) is demographic background, which comprises of questions related to the particulars of the participants. The second section (Section B) consists of open-ended questions to obtain the information on the importance of KPIs. The third section (Section $\mathrm{C}$ ) is on the challenges of 
KPIs implementation in Malaysian PFI projects. The initial process for the semi-structured interview is by short-listing the potential participants based on the specified pre-determined criteria. Targeted participants for this study include individuals who are involved in the O\&M phase of PFI for the selected PFI projects.

\subsection{Results and Discussion}

The analysis starts with the description of the demographic background, followed by the explanation of data analysis procedures. This research then proceeds with the analysis of data using Atlas.ti7@ for determining the importance and challenges of KPI in PFI. The analysis is based on the quotations from the participants which labelled as $P=P$ articipant and $Q=Q$ uotation $(P: Q)$ for the data interpretation.

\subsection{Demographic background}

The demographic data gathered from the Section A were compiled from the participants which consist of their positions in the organisation, working experience, and represented organisations. Table 1 presents the summary of the participants' demographic profile.

Table 1: Demographic background of interviewed participants $(n=10)$.

\begin{tabular}{llcc}
\hline Items & Sub-items & Frequency $(\mathrm{n})$ & Percentage (\%) \\
\hline Stakeholders/Organisations & Public Client & 8 & 80 \\
& FM Contractor & 2 & 20 \\
Designation & Director & 3 & 30 \\
& Engineer & 2 & 20 \\
& Building Surveyor & 3 & 30 \\
& Quantity Surveyor & 1 & 10 \\
& Facility Manager & 1 & 10 \\
Years of Experiences & Less than 5 years & 1 & 10 \\
& 6-10 years & 7 & 70 \\
& 11-15 years & 1 & 10 \\
Academic Background & 16-20 years & 1 & 10 \\
& Civil and Structural Engineer & 3 & 30 \\
& Quantity Surveying & 1 & 10 \\
& Building Surveying & 3 & 30 \\
& Others & 3 & 30 \\
\hline
\end{tabular}

Based on Table 1, it shows that all of the participants' (100\%) designation are from top management and practitioners (directors, engineers, building surveyors, quantity surveyors and facility managers) in the organisation with a majority of them having 6-10 years of work experiences $(70 \%)$. The result indicates that majority of the respondents fit the identified criteria of participants in the interview survey. Hence, making the data obtained more reliable as they came from the most appropriate respondents. According to the Akintoye et al. (2001), the involvement of top management and expert in the PFI is required since decision-making process is limited to the top management. 


\subsection{Data Analysis and Findings}

Section B and C consists of open-ended questions. Issues related to the importance of KPI and the challenges of KPI implementation in Malaysian PFI projects were asked to the participants.

\subsubsection{Importance of KPIs in PFI projects}

In this section, open-ended questions were asked to the participants to get their views on the current KPIs implementation in Malaysia PFI projects specifically for the O\&M phase. Figure 1 presents the findings on the importance of the currents KPIs implemented in the PFI projects. Based on the network of relationship, all of the participants mentioned that KPIs is used as a performance measurement tool to measure the performance of O\&M phase in the PFI projects. Therefore, it is essential to get some views on the current KPIs mainly concerning the importance of KPIs implemented in the PFI projects.

Based on the network, the responses have indicated that the importance of KPIs are to ensure that all the services and facilities provided by the private concessionaire are carried out according to the standard and KPIs as stipulated by the government (coded in IMP-4-1). This coding was verified by Participant 1 in Quotation 17 (P1:Q17) and supported by Participant 9 in Quotation 16 (P9:Q16). The importance of developing and establishing KPIs at the early stage (strategy formulation phase) can influence and give an impact to the implementation of other phases especially for O\&M phase (coded in IMP-4-2). This coding was proved by Participant 1 in Quotation 18 (P1:Q18) and a shared point of views with Participant 8 in Quotation 18 (P8:Q18) and Participant 9 in Quotation 18 (P9:Q18). Furthermore, KPIs is also crucial to be implemented in the O\&M phase because, at this phase, the performance of the concessionaire needs to be monitored and improved to achieve VFM (coded in IMP-4-3). These quotations were discovered from Participant 1 in Quotation 16 (P1:Q16), Participant 3 in Quotation 13 (P3:Q13) and Participant 4 in Quotation 17 (P4:Q17). In addition, KPI is used to measure the performance of PFI projects (coded in IMP-4-4) as indicated by Participant 3, Quotation 12 (P3:Q12) and has been supported by others participants in their quotations (P1:Q15, P4:Q16, P7:Q8, P9:Q17). KPIs is also important in determining the amount of deduction before any payment can be made to the concessionaire (coded in IMP-4-5). This coding was agreed by 3 out of 10 participants with their quotations during the interview session (P4:Q18, P7:Q9, P9:Q19). The other importance of KPIs perceived by Participant 2 in Quotation 10 (P2:Q10) and Participant 1 in Quotation 19 (P1:Q19) is that KPls can be used as a reference in carrying out the maintenance work and can also be referred by both parties (private and public sector) when dealing with O\&M works.

The findings showed that there are several factors identified on the importance of KPIs that helps in measuring and monitoring the PFI projects performance. According to Akbiyikli (2013), during the O\&M phase, services delivery could frequently be measured to determine its compliance with the output specification and payment deductions for the performance failures in accordance with the payment mechanism. This PFI project performance can be measured using KPIs as perceived by Yuan et al. (2009). It is supported by Kagioglou et al. 
(2001); Mladenovic et al. (2013) and Cox et al. (2003) which mentions the KPIs as one of the popular tools used in measuring the performance of PFI projects. As current implementation of PFI in Malaysia, KPIs is identified as a useful tool for measuring and monitoring the PFI projects performance specifically at the O\&M phase as regard to the service delivery and facilities provided by the concessionaire. Thus, KPIs need to be well established at the early stage because it should reflect the goals of the other phases especially O\&M phase as identified as a critical phase as agreed by Yuan et al. (2009) and Akbiyikli (2013).

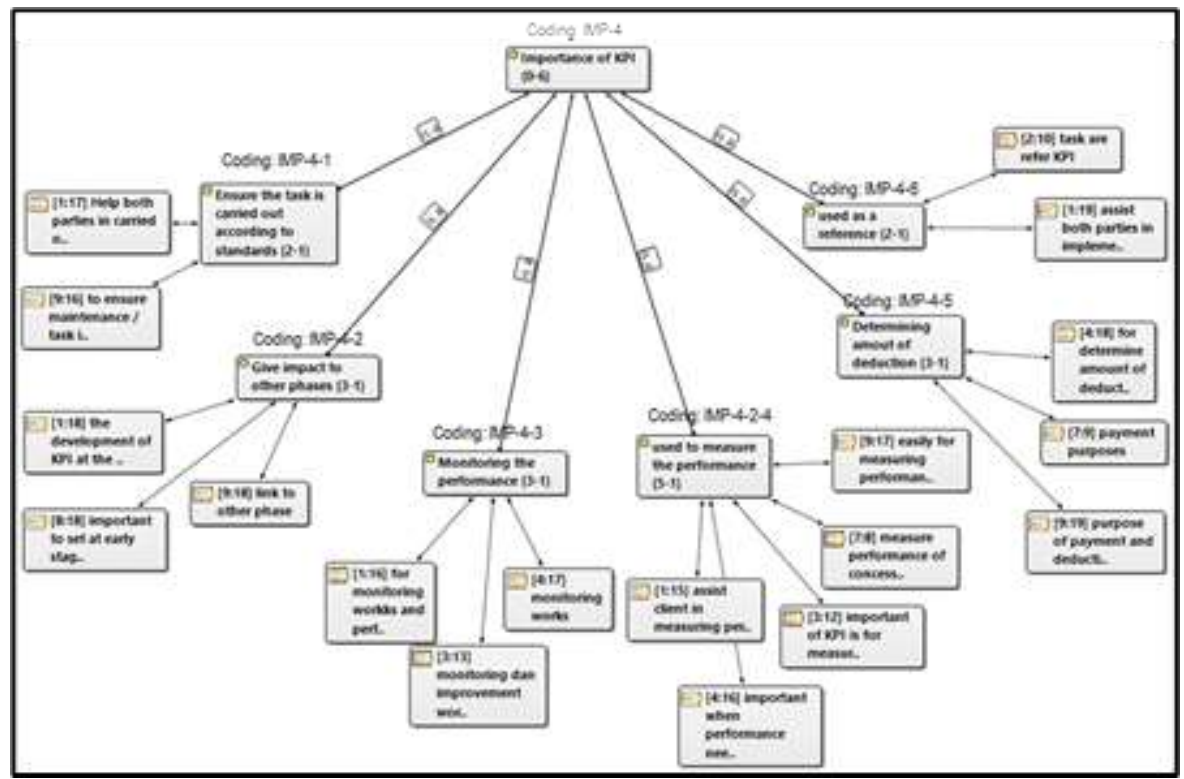

Figure 1: Importance of KPIs implementation in PFI projects

\subsubsection{Challenges of KPIs in PFI projects}

Even though the importance of the KPIs has been identified in the previous section, however, the implementation of KPls is still lacking. It is due to several challenges faced by the stakeholders in implementing this KPI. These challenges can affect the implementation of PFI projects, and further, it can lead to poor and failure PFI projects performance.

Figure 2 shows the network of relationship for the identified challenges of KPIs in PFI implementation (coded in $\mathrm{CH}-4$ ). The first factor identified from the interview session is that the existing built KPIs is too general. This quotation was provided by Participant 5 in Quotation 10 (P5:Q10) and verified by most of the participants involved in the interview session (P7:Q6, P6:Q3, P8:Q5, P10:Q10, P8:Q10). The next factors as revealed by the participants is on the contents of KPIs. The current KPIs are too vague (coded in $\mathrm{CH}-4-2$ ). This coding was verified by 3 out of 10 participants with their quotations (P2:Q9, P3:Q10, P8:Q11). Further, the existing KPIs used for the PFI projects are difficult to understand 
(coded in CH-4-3). The answer was provided by Participant 3, Quotation 11 (P3:Q11). The importance of implementing KPIs in PFI is to measure the performance of PFI project. However, the current KPIs in practice as perceived by the Participants 7 in Quotation 7 (P7:Q7) is difficult to be measured (coded in $\mathrm{CH}-4-4)$. It is due to the weakness, and some of the KPIs is not practical to be implemented in practice. This statement falls under coding $\mathrm{CH}-4-5$. It was verified by Participant 8 in Quotation 13 (P8:Q13) and supported by other participants in their quotations (P8:Q14, P8:Q15, P6:Q4, P6:Q7, P4:Q15). The implementation of KPIs also depends on the other documents (coded in $\mathrm{CH}-4-6$ ). This quotation was provided by Participant 9, Quotation14 (P9:Q14). There is a relationship between KPI, the concession agreement, and output specifications. Therefore, development of KPI at the early stage is very crucial because it links with other documents when entering the other phase of PFI projects.

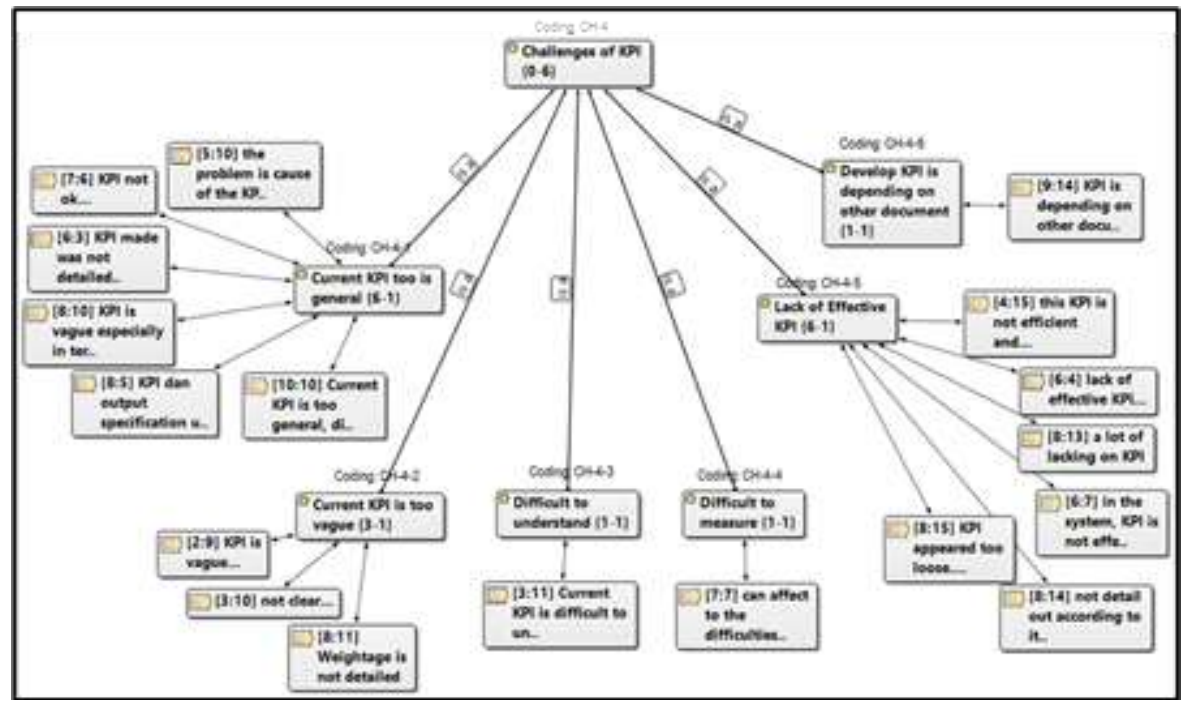

Figure 2: Challenges of KPIs implementation in PFI projects.

From these identified challenges, it shows that the current KPIs do not meet the criteria that caused difficulties in measuring and monitoring the performance of PFI projects. Therefore, there is an importance to select and develop useful KPIs according to the criteria in choosing good indicators.

Even though several studies on KPIs have been conducted with the aim of improving the performances, but KPIs are continuously being debated (Ismail, 2012; Khaderi \& Aziz, 2010). The findings on the challenges in KPIs implementation were identified, and it showed that the current KPIs are lacking in fulfilling the criteria of a good indicator. These identified challenges are parallel with the previous studies by David \& Steve (2012); Lawther \& Martin (2014); Javed et al. (2013b); Toor \& Ogunlana (2010), which indicated that KPIs is lack of 
clarity, difficult to understand, too complicated and some KPIs are too general. These factors will lead to the failure and poor projects performance. The findings illustrate that there is a need to establish an effective KPI for measuring and monitoring the performance of PFI projects to accomplish the project goals and VFM. Concerning that, the development of KPIs should be actively applied to measure performance towards the achievement of certain goals (Shahin \& Mahbod, 2007). Hence, the results support the justification to establish effective KPIs as a measuring tool by considering the important criteria to be embraced when selecting KPIs to ensure more relevant KPIs can be constructed and can be used effectively and efficiently.

\subsection{Conclusion}

This paper has presented the qualitative research on the implementation of KPIs in Malaysia $\mathrm{PFI}$ projects. It shows that the implementation of KPIs in PFI is an urgent issue to be resolved as this will affect the performance of PFI where it involves a lengthy period of concession. In addition, it has also documented the above findings on the importance and challenges of KPIs implementation in Malaysia PFI projects. The determination of the importance and challenges of KPIs will help the stakeholders to improve the current performance measurement tool and simultaneously can enhance the credibility of the public in measuring the PFI projects performance. In addition, it can also improve clients' satisfaction and gain the best VFM. Therefore, it is vital for the Malaysian Government to develop an effective performance measurement tool for measuring PFI projects performance especially for the critical phase of O\&M that involved a lengthy concession period.

The research presented in this paper is initially and a part of an ongoing $\mathrm{PhD}$ research at the Faculty of Architecture, Planning and Surveying, UiTM to develop a performance measurement tool for PFI projects in Malaysia. The result of the study will provide an insight into the Malaysian construction project development and form the basis of a valuable guideline, especially to the public and private sectors in Malaysia.

\section{References}

Akbıyıklı, R. (2013). Performance Assessment of A Private Finance Initiative Road Project. Transport, 28(February 2015), 11-24.

Akintoye, A., Beck, M., Hardcastle, C., Chinyio, E And Asenova, D (2001). Standardised Framework For Risk Assessment and Management of Private Finance Initiative Projects, Report No. 5 Department Of Building And Surveying. Glasgow Caledonian University.

Centre For Construction Innovation For Constructing Excellence In The North West (2006). KPI Gives An Interior/Exterior View of Business. Manchester: Centre For Construction Innovation.

Cox, R. F., Issa, R. R. A., \& Ahrens, D. (2003). Management's Perception of Key Performance Indicators For Construction. Journal of Construction Engineering And Management, 129(2), 142-151.

David, \& Steve. (2012). The Top Ten Risks That Auditors Should Be Aware of When Reviewing The Operational 
Phase of PFI Schemes. HM Treasury.

Hodge, G. A. (2004). The Risky Business Of Public - Private Partnerships. Symposium, 63(December), 37-49.

House Of Commons. (2003). The Operational Performance Of PFI Prisons: Forty-Ninth Report Of Session 20022003, (December).

Isa, H. M., Ismail, K., Zainol, H., \& Othman, M. F. (2016). Tracking Architectural Defects In University Building In Malaysia. MATEC Web Of Conferences, 66 (00017), 2-7.

Ismail, K. (2012). A Value For Money Assessment Framework For Public Private Partnership Approach, A Phd, Thesis. Malaysia.

Ismail, S. (2009). Key Performance Indicator For Private Finance Initiative In Malaysia, A Phd, Thesis. Malaysia.

Javed, A. A., Lam, P. T. I., \& Chan, A. P. C. (2013a). A Model Framework Of Output Specifications For Hospital PPP/PFI Projects. Journal Of Facilities Management, 31(13), 610-633.

Javed, A. A., Lam, P. T. I., \& Zou, P. X. W. (2013b). Output-Based Specifications For PPP Projects: Lessons For Facilities Management From Australia. Journal Of Facilities Management, 11(1), 5-30.

Kagioglou, M., Cooper, R., \& Aouad, G. (2001). Performance Management In Construction: A Conceptual Framework. Journal Of Construction Management \& Economics, 19(1), 85-95.

Khaderi, S. S., \& Aziz, A. R. A. (2010). Adoption Of Private Finance Initiative (PFI) In Malaysian Public Works Projects: Are We Ready? CIB TG72 World Building Congress, 105-120.

Lawther, W. C., \& Martin, L. (2014). Availability Payments And Key Performance Indicators: Challenges For Effective Implementation Of Performance Management Systems In Transportation Public-Private Partnerships. Public Works Management \& Policy, 19(5), 219-234.

Liu, J., Love, P. E. D. D., Smith, J., Regan, M., \& Palaneeswaran, E. (2015). Review Of Performance Measurement: Implications For Public-Private Partnerships. Built Environment Project And Asset Management, 5(1), 35-51.

Liu, J., Love, P. E. D., Davis, P. R., Smith, J., \& Regan, M. (2013). Performance Measurement Framework In PPP Projects.

Mladenovic, G., Vajdic, N., Wündsch, B., \& Temeljotov-Salaj, A. (2013). Use Of Key Performance Indicators For PPP Transport Projects To Meet Stakeholders' Performance Objectives. Built Environment Project And Asset Management, 3(2), 228-249.

Molenaar, K., Garvin, M., Proctor, G., \& Navarro, D. (2011). Key Performance Indicators In Public-Private Partnerships, (March), 120.

NAO. (2003). The Operational Performance Of PFI Prisons, (June), 55.

NAO. (2010). The Performance And Management of Hospital PFI Contracts, 68.

Oyedele, L. O. (2013). Avoiding Performance Failure Payment Deductions In PFI/PPP Projects: A Model Of Critical Success Factors. Journal of Performance of Constructed Facilities, (June), 259.

Regan, M., Smith, J., \& Love, P. E. D. (2011). The Impact of The Capital Market Collapse on Public-Private Partnership Infrastructure Projects. Journal Of Construction Engineering And Management, 137(1), 6-16. 
Robinson, H. S. H., \& Scott, J. (2009). Service Delivery And Performance Monitoring In PFI/PPP Projects. Construction Management and Economics, 27(2), 181-197.

Rusmani, N. (2010). Public Private Partnership in New Zealand and Malaysia.

Sarantakos, S (2012). Social Research (4th Edition). London: Palgrave Macmillan.

Shahin, A., \& Mahbod, M. A. (2007). Prioritization of Key Performance Indicators. International Journal of Productivity and Performance Management, 56(3), 226-240.

Takim, R., R, A. R., Ismail, K., \& C.O, E. (2008). The Acceptability of Private Finance Initiative (PFI) Scheme in Malaysia. Asian Social Science, 4(12), 71-82.

Toor, S.-R., \& Ogunlana, S. O. (2010). Beyond The "Iron Triangle": Stakeholder Perception of Key Performance Indicators (KPIs) For Large-Scale Public Sector Development Projects. International Journal Of Project Management, 28(3), 228-236.

Universiti Teknologi MARA (2015). Laporan Audit Fasiliti \& Perkhidmatan. Perak. Universiti Teknologi Mara, Cawangan Perak.

Universiti Teknologi MARA (2016). Laporan Prestasi Konsesi. Selangor. Bahagian Dasar Operasi PFI, Pejabat Pembangunan Infrastruktur.

VAGO. (2002). Report Of The Auditor-General on The Finances of The State of Victoria, 2001-2002.

Yescombe, E. R. (2008). The Social Sector : PFI Schools Projects In The U. K., (November), 1-18.

Yong, H. K. (2010). Public-Private Partnerships Policy and Practice, London: C. Secretariat.

Yuan, J., Zeng, A. Y., Skibniewski, M. J., \& Li, Q. (2009). Selection of Performance Objectives and Key Performance Indicators in Public-Private Partnership Projects to Achieve Value for Money. Construction Management and Economics, 27(3), 253-270. 